\title{
ChemComm
}

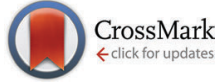

Cite this: Chem. Commun., 2014, 50, 15541

Received 8th October 2014, Accepted 24th October 2014

DOI: $10.1039 / \mathrm{c} 4 \mathrm{cc} 07941 \mathrm{~h}$

www.rsc.org/chemcomm

\section{Exceptionally strong hydrogels through self-assembly of an indole-capped dipeptide $\dagger$}

\author{
Adam D. Martin, Andrew B. Robinson, Alexander F. Mason, \\ Jonathan P. Wojciechowski and Pall Thordarson*
}

The synthesis of a new hydrogelator with an indole capping group, 1, is reported. 1 forms exceptionally strong hydrogels in a variety of environments, with values for the storage modulus $G^{\prime}$ amongst the highest reported for supramolecular hydrogels. These gels exhibit strong bundling characteristics, which gives the high values for $G^{\prime}$ observed. Cell viability studies show that at low concentrations, 1 is biocompatible, however upon self-assembly at higher concentrations, cytotoxic effects are observed.

Supramolecular or self-assembled hydrogels are an important class of materials that are rapidly gaining prominence, due to applications such as wound repair, ${ }^{1,2}$ tissue engineering, ${ }^{3,4}$ drug delivery ${ }^{5,6}$ and biosensing. ${ }^{7}$ Hydrogels composed of di- or tripeptides are a subset of these remarkable materials, and usually rely on hydrogen bonding between amide groups in conjunction with aromatic stacking interactions to drive self-assembly. To this end, the diphenylalanine sequence (-FF) is perhaps the most well-studied of the dipeptides, with its self-assembly being partially driven by the two phenyl groups present on the amino acids. ${ }^{8}$ Since the initial paper reporting the gelation properties of Fmoc-FF (where Fmoc = fluorenylmethoxycarbonyl) there have been a number of reports investigating the use of Fmoc-FF for biocatalysis, drug release and cell culturing. ${ }^{9-12}$

Due to their supramolecular nature, these hydrogels are typically weak, with storage moduli typically around $1000 \mathrm{~Pa}$ or less. The value of the storage and loss modulus of a supramolecular gel is also dependent on the method through which the gel network is formed, for example in $\mathrm{pH}$ triggered gelation the final $\mathrm{pH}$ and nature of the $\mathrm{pH}$ trigger plays a crucial role in the final values obtained through rheology. ${ }^{13}$

School of Chemistry, The Australian Centre for Nanomedicine and the ARC Centre of Excellence for Convergent Bio-Nano Science and Technology,

The University of New South Wales, Sydney, 2052, NSW, Australia.

E-mail: p.thordarson@unsw.edu.au; Fax: +61 (0)2 9385 6141;

Tel: $+61(0) 293854478$

$\dagger$ Electronic supplementary information (ESI) available: Experimental procedures, full characterisation including HPLC, NMR and MS spectra for 1. See DOI: $10.1039 / \mathrm{c} 4 \mathrm{cc} 07941 \mathrm{~h}$
Limited examples of "strong" hydrogels exist currently, including peptide-based hydrogels reinforced with carbon nanotubes or long alkyl chains to maximise van der Waals interactions. ${ }^{14,15}$ In many cases hybrid systems are employed in order to increase gel strength, such as the use of peptides encapsulating non-steroidal antiinflammatory drugs (NSAIDs), ${ }^{16}$ long peptides linked through $\mathrm{Ca}^{2+}$ ions ${ }^{17}$ or peptide-based dendrimers that act as binding agents for dispersing clay nanosheets, resulting in very high storage moduli. ${ }^{18}$ Certain di- and tripeptide sequences bearing Fmoc capping groups have also been shown to exhibit high storage moduli, ${ }^{19,20}$ but self-assembled hydrogels with storage moduli exceeding $10^{5} \mathrm{~Pa}$ remain elusive.

Indole is a versatile naturally occurring compound and is commonly found in a wide variety of natural products, including the amino acid tryptophan. Its derivatives are used in a variety of fragrances, ${ }^{21}$ and as pharmaceutical and synthetic biological compounds. ${ }^{2-24}$ 3-Indoleacetic acid is better known as auxin, and this compound and its associated derivatives play a crucial role in the growth of plants. ${ }^{25}$ Despite the widespread use of indoles throughout chemistry, no examples of supramolecular hydrogels employing indole as a capping group exist. This is surprising, given the ability of the indole moiety to drive self-assembly both through its aromaticity and potential for hydrogen bonding. Herein, we report the synthesis of the first dipeptide capped with an indole group; indole-3-acetic acid diphenylalanine, that is able to form stable and exceptionally strong hydrogels, in addition to the physical and toxicological characterisation of these novel tough gels.

Compound 1 (shown in Fig. 1) was prepared via solid phase peptide synthesis using commercially available indole-3-acetic acid (see ESI $\dagger$ for details on the synthesis, characterisation and preparation of gels of $\mathbf{1}$ ) and its gelation properties investigated. Compound $\mathbf{1}$ is able to form gels in a variety of different solvents, such as $1 \mathrm{mM}$ phosphate buffer solution (PBS), where the solution is heated to $90{ }^{\circ} \mathrm{C}$ and allowed to cool, forming a transparent gel that gradually changes to an opaque gel over time. Compound 1 can also form a gel if dissolved in DMSO and then diluted with water, or through a $\mathrm{pH}$ switching mechanism where one equivalent of base is added to solubilise 
<smiles>O=C(Cc1c[nH]c2ccccc12)N[C@@H](Cc1ccccc1)C(=O)N[C@@H](Cc1ccccc1)C(=O)O</smiles>

1

Fig. 1 Chemical structure of 1.

the gelator, followed by the addition of one equivalent of glucono- $\delta$-lactone $(\mathrm{GdL})$ to lower the $\mathrm{pH}$. In both of the preceding examples, opaque gels are formed over the course of 5-10 minutes. Only in the $\mathrm{pH}$ switching gel is sonication required to aid gelation, in all other cases gentle agitation of the gelator solution is sufficient to dissolve the gelator. In all solvents the minimum gel concentration was found to be about $0.4 \%(\mathrm{w} / \mathrm{v})$.

The secondary structure of the gel was probed using circular dichroism (CD) and attenuated total reflectance-infrared spectroscopy (ATR-IR). CD measurements were taken at a concentration of $0.05 \%(\mathrm{w} / \mathrm{v})$, a $20 \times$ dilution of the initial $1 \%(\mathrm{w} / \mathrm{v})$ gel that was prepared, and the sole negative peak at $220 \mathrm{~nm}$ is indicative of a $\beta$-sheet arrangement (Fig. 2a). This is supported by the ATR-IR data, which shows peaks in the amide I and II regions at 1643 and $1531 \mathrm{~cm}^{-1}$ respectively (Fig. $2 \mathrm{~b}$ ).

Substantial hydrogen bonding is reflected in the rheology of hydrogels of $\mathbf{1}$, which display extremely high values for the storage modulus, $G^{\prime}$. In fact, the values of $G^{\prime}$ recorded for hydrogels composed of $\mathbf{1}$ make it one of the strongest supramolecular gels reported to date. This is more than likely due to the potential for extra hydrogen bonding through the indole moiety, or perhaps (a)

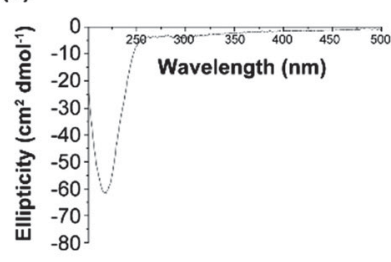

(c)

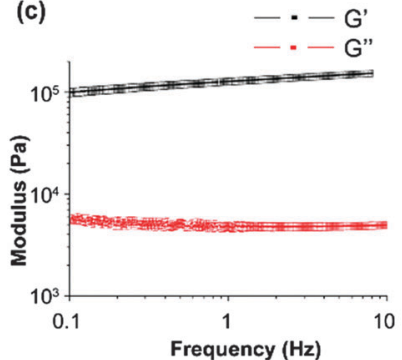

(b)

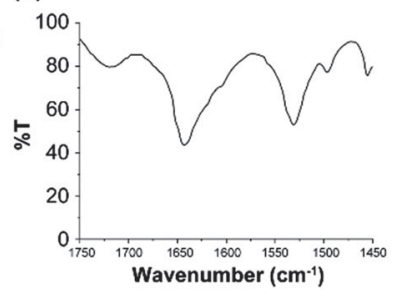

(d)

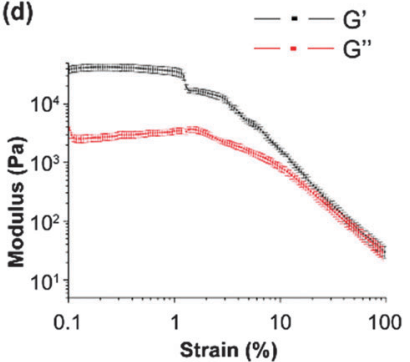

Fig. 2 (a) CD spectrum of a $1 \%(w / v)$ hydrogel of 1 dispersed in water to achieve a final concentration of $0.05 \%(\mathrm{w} / \mathrm{v})$ and $(\mathrm{b})$ ATR-IR spectrum of a $1 \%(\mathrm{w} / \mathrm{v})$ hydrogel composed of 1 , showing the amide I and II regions. (c) Frequency sweep and (d) strain sweep for a 1\% (w/v) hydrogel of 1 in milliQ water at $25{ }^{\circ} \mathrm{C}$, where error bars denote two standard deviations from the log-averaged mean. $\pi \cdots \pi$ interactions between the indole and the phenylalanine moiety. Values for $G^{\prime}$ in the region of over $10^{5} \mathrm{~Pa}$ (Fig. 2c) and reaching as high as $3 \times 10^{5} \mathrm{~Pa}$ for gels formed by the $\mathrm{pH}$ switch, show that hydrogels of $\mathbf{1}$ are remarkably strong, and potentially suitable for a wide range of different mechanical applications. Strain sweep measurements show that the hydrogel fails at strains of just over $50 \%$ (Fig. 2d). By changing the method of gel formation from a pH switch to a solvent switch using DMSO (Fig. S5, ESI†) or temperature switch in $1 \mathrm{mM}$ PBS (Fig. S6, ESI $\dagger$ ), it is possible to lower the $G^{\prime}$ down to or below $10^{4} \mathrm{~Pa}$. It should be noted that for hydrogels formed via the pH switch method, sonication time had little effect on the final $G^{\prime}$ values recorded.

The impressively large $G^{\prime}$ values measured may also be due to the formation of large fibrous networks, as upon slicing open or coating a gel onto a substrate, millimetre-length fibres are visible with the naked eye. In order to investigate the behaviour of the hydrogel on the nanoscale, both TEM and AFM measurements were performed. TEM micrographs show long, straight fibres (Fig. 3a and b).

The TEM micrographs indicate that fibres vary in thickness from approximately $100-400 \mathrm{~nm}$, with no particular preferred size or orientation. Interestingly, no branching of the fibres is observed in these TEM images. Branching of nanofibres is commonly observed in many supramolecular hydrogels, and is often identified as a stage in the growth of gel networks. The lack of branching observed makes the high storage modulus observed in the gel network of $\mathbf{1}$ even more remarkable.

This lack of branching is further confirmed by the AFM images that were taken upon spin coating a solution of the gelator onto a freshly cleaved mica substrate. In these images, although they cross over each other, no branching is observed and the fibres are seen to strongly associate with each other, instead of the mica substrate (Fig. 3c). This strong attractive (a)

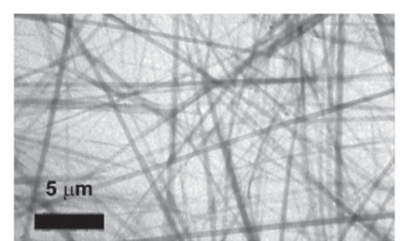

(c)

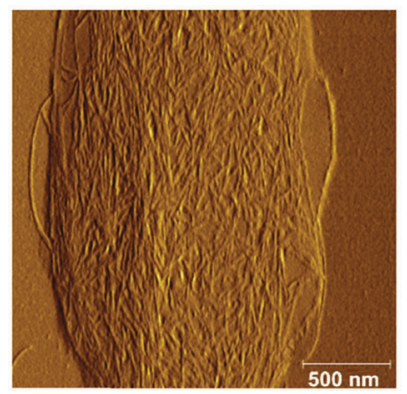

(b)

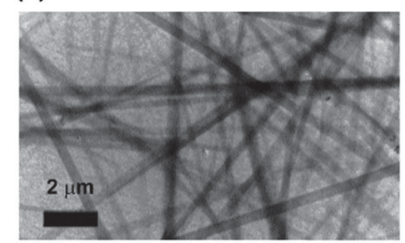

(d)

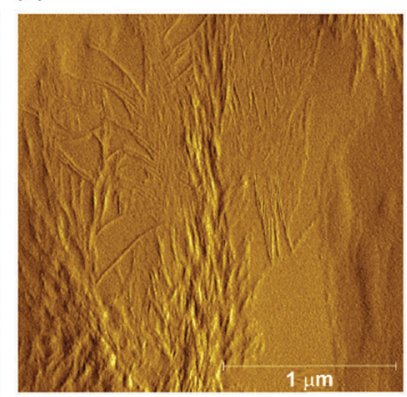

Fig. 3 (a) and (b) TEM images of a dried $1 \%(w / v)$ hydrogel of 1 at different magnifications deposited on formvar coated copper grids. AFM amplitude images of (c) dried solutions of a hydrogel of 1 at $1 \%(w / v)$ and (d) $0.01 \%$ $(\mathrm{w} / \mathrm{v})$ spin-coated onto mica. 
(a)
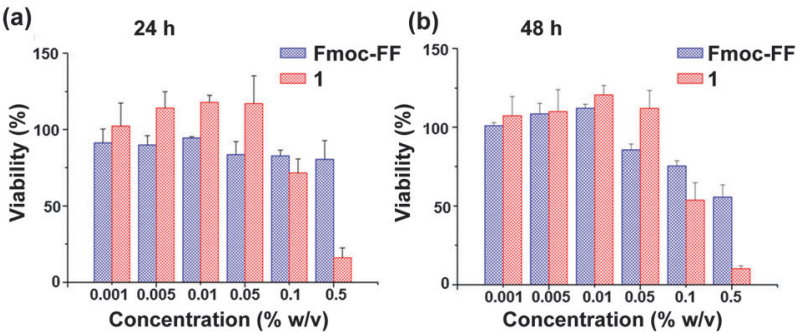

Fig. 4 (a) Cell viability studies of 1 compared to Fmoc-FF, performed on HeLa cells at time points of $24 \mathrm{~h}$ and (b) $48 \mathrm{~h}$. Error bars denote the standard deviations $(n=3)$

tendency between nanofibres explains the high values for the storage modulus that have been measured for hydrogels of 1 and gives an insight into the morphology of hydrogels of $\mathbf{1}$ at the nanoscale. It was recently postulated that the two main ways to increase the stiffness of a gel network was to either increase either the number of fibres $(N)$ in a bundle or the persistence length $\left(l_{\mathrm{p}}\right)$ of fibres in a bundle. ${ }^{26}$ From the AFM images observed, it is clear that for this system, $N$ is large and therefore results in the exceptionally high storage modulus observed for these gel networks.

Unfortunately, the strong association of these shorter nanofibres precludes an accurate measurement of their height, however the isolated nanofibres present in the images have a height of approximately $2 \mathrm{~nm}$, which is similar in height to the proposed $J$-aggregates of Fmoc-FF that self-assemble into nanofibres. ${ }^{8}$ Dilution of the gel solution was undertaken in order to attempt to disperse these short, highly associated nanofibres, however strong inter-fibre association is still observed even in dilute solutions (Fig. 3d).

The strength of these hydrogels makes them an ideal candidate for biological applications, such as tissue engineering. As such, their biocompatibility was investigated using an alamarBlue colourimetric assay on HeLa cells. It can be seen from Fig. 4a that after $24 \mathrm{~h}, \mathbf{1}$ displays comparable biocompatibility relative to Fmoc-FF for concentrations up to $0.1 \%(\mathrm{w} / \mathrm{v})$. At higher concentrations $(>0.1 \%(\mathrm{w} / \mathrm{v})$ or $>2.1 \mathrm{mM})$, which is well beyond the limit of ordinary cytotoxicity studies (around $0.05-0.5 \mathrm{mM}$ ), ${ }^{27-29}$ some cell toxicity can be seen. We propose that the cell toxicity observed is due to the salts present in the cell culture media preventing the bundling that is observed in the fibres, resulting in smaller aggregates that most likely interact with the cell membrane. Experiments where cells were seeded on top of pre-formed gels of $\mathbf{1}$ were also performed, with cell death occurring after $24 \mathrm{~h}$ for all samples. This is presumably due to the salts in the cell culture media rapidly breaking down the large fibre bundles into smaller, proto-fibres. These bundles are most likely held together through electrostatic interactions due to the polar indole capping group, and addition of salts act to screen these charges, disassembling the fibre bundles into smaller proto-fibres which interact with the cell membrane and result in cell death. ${ }^{30}$ Indeed, increased cytotoxicity has previously been observed in peptide amphiphiles where alterations to the cohesiveness of the fibres results in faster uptake into cells and resultant cell death. ${ }^{31}$ The effect of salts on fibre formation is supported by the lack of gelation in a DMSODMEM solvent mixture, in contrast to DMSO- $\mathrm{H}_{2} \mathrm{O}$, which forms stable hydrogels, and the degradation of hydrogels of $\mathbf{1}$ when exposed to a concentrated solution of $\mathrm{NaCl}$.

In conclusion, we have synthesised the first peptide bearing an indole capping group, $\mathbf{1}$, and shown that this dipeptide forms gels under a variety of different solvent conditions and at low concentrations. These hydrogels have been extensively characterised using spectroscopic and microscopy techniques and display a $\beta$-sheet secondary structure. Rheology measurements reveal that hydrogels of $\mathbf{1}$ are remarkably strong, with a storage modulus reaching $3 \times 10^{5} \mathrm{~Pa}$, making it one of the strongest supramolecular hydrogels reported. An insight into the strength of these gels comes from microscopy studies, which reveal a low degree of branching and a high degree of fibre bundling, and this extensive bundling goes some way to explaining the large values for $G^{\prime}$. Cell viability studies of $\mathbf{1}$ using HeLa cells show cytotoxicity which is comparable to Fmoc-FF for concentrations up to $0.1 \%(\mathrm{w} / \mathrm{v})$, followed by cytotoxic effects as $\mathbf{1}$ starts to self-assemble into higher-order structures. The salts present in the cell culture media are thought to play a role in the inability of $\mathbf{1}$ to self-assemble into bundles, with the resulting smaller supramolecular aggregates demonstrating cytotoxic effects, most likely through interactions with the cell membrane.

We would like to thank the Mark Wainwright Analytical Centre (UNSW) for access to instruments. We acknowledge the Australian Research Council for Discovery Project Grant (DP130101512), an ARC Centre of Excellence Grant (CE140100036) and a Future Fellowship to PT (FT120100101), support from the Commonwealth Science and Industrial Research Organisation (CSIRO) to PT and ABR and the Australian Government for PhD scholarships to ABR, AFM and JPW.

\section{Notes and references}

1 R. V. Ulijn, N. Bibi, V. Jayawarna, P. D. Thornton, S. J. Todd, R. J. Mart, A. M. Smith and J. E. Gough, Mater. Today, 2007, 10, 40.

2 C. Ghobril, K. Charoen, E. K. Rodriguez, A. Nazarian and M. W. Grinstaff, Angew. Chem., Int. Ed., 2013, 52, 14070.

3 J. L. Drury and D. J. Mooney, Biomaterials, 2003, 24, 4337.

4 W. T. Truong, Y. Su, J. T. Meijer, P. Thordarson and F. Braet, Chem. - Asian J., 2011, 6, 30.

5 M. C. Branco and J. P. Schneider, Acta Biomater., 2009, 5, 817.

6 A. Altunbas and D. J. Pochan, Top. Curr. Chem., 2011, 310, 135.

7 A. Yoshimura, Y. Miyahara, N. Kasagi, H. Yamane, A. Ojida and I. Himachi, J. Am. Chem. Soc., 2004, 126, 12204.

8 M. Smith, R. J. Williams, C. Tang, P. Coppo, R. F. Collins, M. L. Turner, A. Saiani and R. V. Ulijn, Adv. Mater., 2008, 20, 37.

9 J. H. Kim, S. Y. Lim, D. H. Nam, J. Ryu, S. H. Ku and C. B. Park, Biosens. Bioelectron., 2011, 26, 1860.

10 T. Liebmann, S. Rydholm, V. Akpe and H. Brismar, BMC Biotechnol., $2007,7,88$.

11 A. Mahler, M. Reches, M. Rechter, S. Cohen and E. Gazit, Adv. Mater., 2006, 18, 1365.

12 G. Scott, S. Roy, Y. M. Abul-Haija, S. Fleming, S. Bai and R. V. Ulijn, Langmuir, 2013, 29, 14321.

13 J. Raeburn, G. Pont, L. Chen, Y. Cesbron, R. Levy and D. J. Adams, Soft Matter, 2012, 8, 1168.

14 S. K. Mandal, T. Kar and P. K. Das, Chem. - Eur. J., 2013, 19, 12486. 15 A. Pal and J. Dey, Soft Matter, 2011, 7, 10369. 
16 J. Li, Y. Kuang, Y. Gao, X. Du, J. Shi and B. Xu, J. Am. Chem. Soc., 2013, 135, 542.

17 J. Shi, Y. Gao, Y. Zhang, Y. Pan and B. Xu, Langmuir, 2011, 27, 14425. 18 Q. Wang, J. L. Mynar, M. Yoshida, E. Lee, M. Lee, K. Okuro, K. Kinbara and T. Aida, Nature, 2010, 463, 339.

19 V. Jayawarna, S. M. Richardson, A. R. Hirst, N. W. Hodson, A. Saiani, J. E. Gough and R. V. Ulijn, Acta Biomater., 2009, 5, 934.

20 G. Cheng, V. Castalletto, C. M. Moulton, G. E. Newby and I. W. Hamley, Langmuir, 2010, 26, 4990.

21 S. C. Roberts, Nat. Chem. Biol., 2007, 3, 387.

22 R. J. Sundberg, Indoles, Academic Press, London, 1996.

23 R. W. DeSimone, Comb. Chem. High Throughput Screening, 2004, $7,473$.

24 Y. S. Kim and J. A. Milner, J. Nutr. Biochem., 2005, 16, 65.

25 A. W. Woodward and B. Bartel, Ann. Bot., 2005, 95, 705.
26 P. J. H. Kouwer, M. Koepf, V. A. A. Le Sage, M. Jaspers, A. M. van Buul, Z. H. Eksteen-Akeroyd, T. Woltinge, E. Scwartz, H. J. Kitto, R. Hoogenboom, S. J. Picken, R. J. M. Nolte and A. E. Rowan, Nature, 2013, 493, 651.

27 M. Miwa, M. Ura, M. Nishida, N. Sawada, T. Ishikawa, K. Mori, N. Shimma, I. Umeda and H. Ishitsuka, Eur. J. Cancer, 1998, 34, 1274.

28 S. M. Guichard, J. S. Macpherson, I. Mayer, E. Reid, M. Muir, M. Dodds, S. Alexander and D. I. Jodrell, Eur. J. Cancer, 2008, 44, 310.

29 W. T. Truong, Y. Su, D. Gloria, F. Braet and P. Thordarson, Biomater. Sci., 2015, DOI: 10.1039/C4BM00244J.

30 S. M. Sagnella, C. E. Conn, I. Krodkiewska, M. Moghaddam and C. J. Drummond, J. Phys. Chem. B, 2010, 114, 1729.

31 C. J. Newcomb, S. Sur, J. H. Ortony, O. S. Lee, J. B. Matson, J. Boekhoven, J. M. Yu, G. C. Schatz and S. I. Stupp, Nat. Commun., 2014, 5, 3321. 